\title{
Development of decision support system for employee selection using Adaptive Neuro Fuzzy Inference System
}

\author{
Abdullah 'Azzam and Sri Indrawati \\ Industrial Engineering, Universitas Islam Indonesia, Yogyakarta, Indonesia
}

\begin{abstract}
The number of children day care is increasing from year to year. Children day care is categorized as service industry that help parents in caring and educate children. This type of service industry plays a substitute for the family at certain hours, usually during work hours. The common problems in this industry is related to the employee performance. Most of employees have a less understanding about the whole job. Some employees only perform a routine task, i.e. feeding, cleaning and putting the child to sleep. The role in educating children is not performed as well as possible. Therefore, the employee selection is an important process to solve a children day care problem. An effective decision support system is required to optimize the employee selection process. Adaptive neuro fuzzy inference system (ANFIS) is used to develop the decision support system for employee selection process. The data used to build the system is the historical data of employee selection process in children day care. The data shows the characteristic of job applicant that qualified and not qualified. From that data, the system can perform a learning process and give the right decision. The system is able to provide the right decision with an error of 0,00016249 . It means that the decision support system that developed using ANFIS can give the right recommendation for employee selection process.
\end{abstract}

\section{Introduction}

Employee plays an important role for a service industry, therefore an organization should hire a qualified people. An effective employee selection process is needed to achieve that condition. The Children day care is one of service industry that urgently need a qualified employee from a right selection process. The common problems that exist in a children day care is associated with employees with lack of ability in performing a full role of a day care. This problem can disrupt the performance stability of a children daycare as a whole. Therefore, an effective decision support system for employee selection process is required to solve a children day care problem. A decision support system based on some common variables, i.e. age, years of experience and qualification can improve the human decision making capabilities [1].

There are four popular methods used in personel selection, i.e. technique for order preference by similarity to ideal solution (TOPSIS), analytic hierarchy process (AHP), analytic network process (ANP) and expert system (ES) [2]. Human resources selection process is done using a fuzzy technique for order preference by similarity to ideal solution (FTOPSIS) to minimize errors in decision making process [3]. System dynamics is effectively used in human resource dynamic problems [4].

A decision support system for employee recruitment process for textile industry in Indonesia have been designed using fuzzy Mamdani [5]. There are four types of data that being used, i.e. psychological tests, physical tests, interview tests and health tests. The system can perform a decision with an error point of $0-5 \%$. A fuzzy analytic hierarchy process is used to develop a decision making system for employee recruitment in an Indonesian telecommunication industry [6]. There are five important data in this system, i.e. age, gender, education, work experience and desired salary. A decision support system developed for employee selection using the fuzzy MADM (multiple attribute decision making) [7]. The system can provide rankings according to the quality of each applicant. A fuzzy technique of order preference by similarity to ideal solution (TOPSIS) is applied for personnel selection to reduce the risks of hiring unqualified employee [8].

A decision support system also can be done with adaptive neuro fuzzy inference system (ANFIS). A decision support system developed for flood forecasting in Korea using ANFIS [9]. This system can forecast and give an early warning from heavy storm in real time. A computer aided decision support system successfully created using ANFIS to detect glaucoma in monocular fundus images [10]. Based on that research, the proposed method can perform a better accuracy for glaucoma detection that neural network and support vector machine classifier (SVM). ANFIS have already successfully used to develop a decision support system in many medical fields to diagnose and monitor a various disease [11].

ANFIS also can be applied in other fields. ANFIS based system has been developed to select bank loan installments package in Saudi Arabia [12]. The research

\footnotetext{
Corresponding author: abdullah.azzam@uii.ac.id
} 
generated 10,000 random sample data with different possible. ANFIS also can create an effective and accurate decision support system to determine major of the prospective student in a vocational school [13]. There are three determinant variables, i.e. national exam scores, interesting to the majors and placement test score.

The use of ANFIS method on decision support system with employee selection process data as training data is expected to give the right decision in recruitment process. The employee selection process data consist of a good performance employee and unqualified applicants. ANFIS method can speed up the process of knowledge translation where if using fuzzy inferences it takes time in setting the function of membership while in artificial neural network can be used learning technique that can shorten the time. The instructional technique in this study uses supervised learning techniques where the technique requires previous available data.

\section{Basic Theory}

ANFIS is a method that perform as artificial neural network based on Takagi-Sugeno fuzzy inference system. This method is developed in 1990 where this method a strength that can be drawn from artificial neural networks concept and fuzzy logic principles because ANFIS combines these two things [14]. The inference system used is to apply IF-THEN rules that have the ability to understand non-linear function problems [15]. The ANFIS methods can be used more efficiently and optimally, if the best parameters can be used from the parameters obtained from the genetic algorithm [16].

\section{Research Method}

The research is done in a chidren day care located in Yogyakarta, Indonesia. There are three main stage that being used, i.e. data collection, development of decision support system with ANFIS method and performance analysis. Historical data of employee reqruitment process is used as initial data. There are two kind data, interview and observation process result. The data then being adjusted before it is used to develop a fuzzy system using MATLAB software. The next process is setting the data training parameters and train the initial data. After ANFIS generates a model, the model is tested for validation. The purpose of this process is know the accuracy in modeling the system. The ANFIS model is validated by comparing the output of the data that has been done from data training process with the actual data. The best model if preform with a small error. A graphical user interface then being develop to make an easier interaction between the user with the decision support system.

\section{Result and Discussion}

Decision support systems that developed for employee selection can displays or deliver the result after the user already input the data from applicants. The context diagram can be seen in Figure 1. The system can help the decision maker to decide an applicant is accepted or not based on two types of selection process, observation and interview as seen in Appendix 1. There are eight determinants variables that being used, i.e. innitiative score, friendly score, responsiveness score, interaction with parents score, cooperation score, interaction with kids score, commitment score and expected sallary.

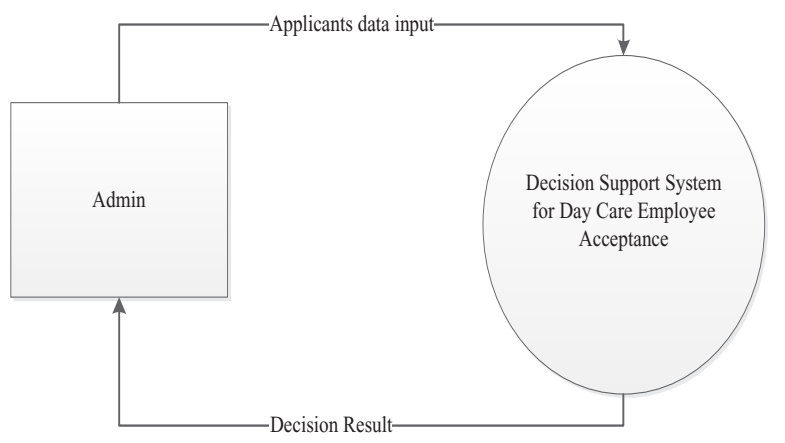

Fig. 1. Context diagram of Decision Support System for employee selection

The decision support system is built using Matlab and ANFIS method. The first step is to adjust the employee acceptance data in Appendix 1 so it can be process in decision support system. The adjustment is done with changing the status data into binary numbers, 1 is for accepted applicants and 0 for rejected applicants. Data adjustment also being done with summing the value at each type of employee selection process, i.e. observation and interview. The results of the initial data adjustment can be seen in Table 1.

Table 1. Data Adjustment

\begin{tabular}{cccccccccc}
\hline No & Name & Observation & Interview & Status & No & Name & Observation & Interview & Status \\
\hline 1 & Widyarti & 2,5 & 3,5 & 1 & 6 & Santi & 2,5 & 2 & 0 \\
2 & Putri & 2,7 & 3,5 & 1 & 7 & Susan & 2,5 & 1,5 & 0 \\
3 & April & 2,3 & 3,5 & 1 & 8 & Umi & 1,5 & 2 & 0 \\
4 & Siska & 3,7 & 3 & 1 & 9 & Anggi & 1,3 & 1 & 0 \\
5 & Ningsih & 3,3 & 3 & 1 & 10 & Lestari & 2,3 & 1 & 0 \\
\hline
\end{tabular}


The next step in developing a decision support system for employee selection is to determine membership function. There are three types of membership functions that being used in this research, i.e. high, medium and low. In addition, it is also necessary to specify the type of membership function using Gauss type in order to produce a smoother output. A hybrid training method which is a combination of backpropagation and least square methods is used. This training process is use epoch 100. The result of the training process can be seen in Figure 2.

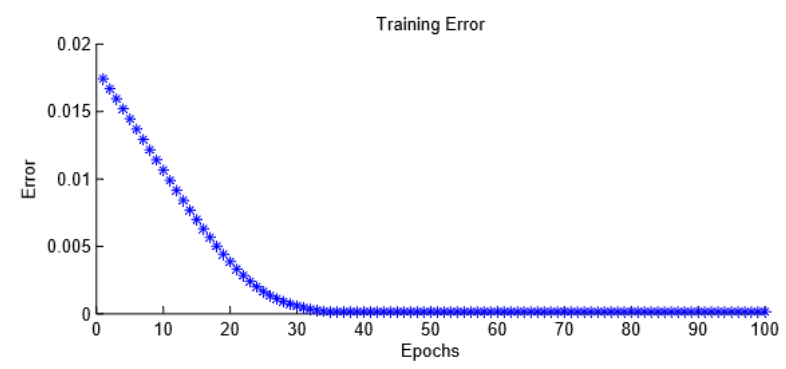

Fig. 2. Training Error

The training error is decreasing starting from epochs 0 to 100 . The error rate resulting from the training process is 0,00016249 and remains at that value starting at epochs 31. The ANFIS performance that already trained using initial data from previous stage can be known by doing a test. The test can be done by plotting the initial data and ANFIS using the same input value. The results of the fuzzy inference system test (FIS) on the ANFIS editor can be seen in Figure 3. The results from the initial data plotting in the form of a blue circle, as a whole coincide with the ANFIS output that symbolized by the red star. This means that there almost no error when the user inputs the data in that range of values.

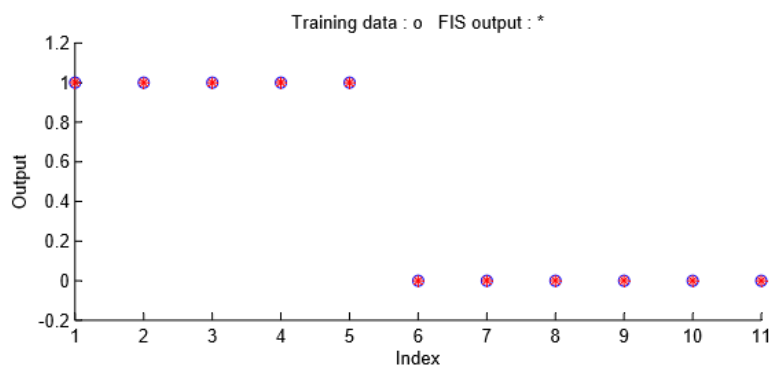

Fig. 3. FIS Test

The data training process is the way used in ANFIS to understand existing data patterns that being used to provide solutions for employee selection problems in children day care. The training process can be run by providing initial input data. The training process in this system uses 11 initial data and will generate the rules of the membership function that have been specified previously. There are nine rules that being generated as seen in Figure 4.
1. If (input1 is in $1 \mathrm{mf} 1$ ) and (input 2 is in $2 \mathrm{mf} 1$ ) then (output is out1 $\mathrm{mf} 1$ ) (1)

2. If (input1 is in $1 \mathrm{mf} 1$ ) and (input 2 is in $2 \mathrm{mf} 2$ ) then (output is out1 $\mathrm{mf} 2$ ) (1)

3. If (input1 is in $1 \mathrm{mf} 1$ ) and (input 2 is in $2 \mathrm{mf} 3$ ) then (output is out $1 \mathrm{mf} 3$ ) (1)

4. If (input1 is in $1 \mathrm{mf} 2$ ) and (input 2 is in $2 \mathrm{mf} 1$ ) then (output is out $1 \mathrm{mf} 4$ ) (1)

5. If (input1 is in $1 \mathrm{mf} 2$ ) and (input 2 is in $2 \mathrm{mf} 2$ ) then (output is out $1 \mathrm{mf} 5$ ) (1)

6. If (input1 is in $1 \mathrm{mf} 2$ ) and (input 2 is in $2 \mathrm{mf} 3$ ) then (output is out1 $\mathrm{mf} 6$ ) (1)

7. If (input1 is in $1 \mathrm{mf} 3$ ) and (input 2 is in $2 \mathrm{mf} 1$ ) then (output is out $1 \mathrm{mf} 7$ ) (1)

8. If (input 1 is in $1 \mathrm{mf} 3$ ) and (input 2 is in $2 \mathrm{mf} 2$ ) then (output is out $1 \mathrm{mf} 8$ ) (1)

9. If (input1 is in $1 \mathrm{mf} 3$ ) and (input 2 is in $2 \mathrm{mf} 3$ ) then (output is out $1 \mathrm{mf} 9$ ) (1)

Fig. 4. The rules

Each new applicants data entered and in accordance with the restrictions or rules that exist then the system will provide the right solution or decision. The result of decision support system for employee selection in children daycare can be seen in Figure 5.
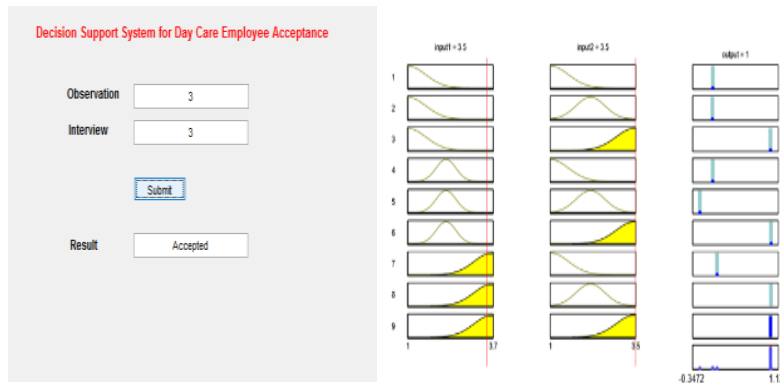

Fig. 5. Implementation

\section{Conclusion}

The decision support system for employee selection in children day care using ANFIS method is successfully being implemented. The system can provide a decision whether the applicants that follows the selection process is accepted or not with a small error value. The error rate resulting from the training process is 0,00016249 . This error is more smaller then other method. The ANFIS performance will be more optimal if it is used a large numbers of data. Because system can learn with more data.

Researchers thank to the support of Industrial Engineering Department, Faculty of Industrial Technology, Universitas Islam Indonesia.

\section{Reference}

1. B. Ngwenya, Application of Decision Support Systems and Its Impact on Human Resources Output: A Study of Selected Universities in Zimbabwe, Journal of Computer Sciences and Applications, Volume 1, No. 3: 46-54, (2013)

2. A.R Afshari,, M. Nikolic, D. Cockalo, Applications Of Fuzzy Decision Making For Personnel Selection Problem - A Review, Journal Of Engineering Management And Competitiveness, Vol. 4, No. 2, pp. 68-77, (2014)

3. K. M. Doka, F. Ahmad, S. N. W. Shamsuddin, W. S. W. Awang, N. Ghazali, Integrated Decision Support System for Human Resource Selection Using

* Corresponding author: abdullah.azzam@uii.ac.id 
TOPSIS Based Models, Applied Mathematical Sciences, Vol. 9, No. 129, pp. 6403 - 6414, http://dx.doi.org/10.12988/ams.2015.53288, (2015)

4. C.B. Richa, Application Of Decision Support System In Human Resource Management In Mfis- A System Dynamics Approach, International Journal of Business and Economic Research, Vol.14, No. 10, pp. 6849-6862, (2016)

5. A. T. Suseno, Penerapan Metode Fuzzy Mamdani Untuk Sistem Pendukung Keputusan Penerimaan Karyawan PT. Primatexco Indonesia, Program Studi Teknik Informatika Universitas Dian Nuswantoro, Semarang, (2009)

6. R. K. Ablhamid, B. Santoso, M. A. Muslim, Decision Making and Evaluation System for Employee Recruitment Using Fuzzy Analytic Hierarchy Process, International Refereed Journal of Engineering and Science (IRJES), Volume 2, Issue 7: 24-31, (2013)

7. D. A. Ramadhani, S. Astuti, Sistem Pendukung Keputusan Penerimaan Pegawai dengan Metode Fuzzy MADM, Techno.com, (2014)

8. M. Mammadova, Z. Jabrayilova, Application of Fuzzy Optimization Method in Decision-Making for Personnel Selection, Intelligent Control and Automation, Volume 5: 190-204, (2014)

9. Jaeeun, Development of Decision Support System for Flood Forecasting and Warning in Urban Stream, Journal of The Korean Society of Civil Engineers, Vol. 28, Issue 6B: 743-750, (2008)
10. S. Kavitha, K. Duraiswamy, An Efficient Decision Support System for Detection of Glaukoma in Fundus Images Using ANFIS, International Journal of Advances in Engineering \& Technology., Vol. 2, Issue 1: 227-240, (2012)

11. N. Walia, S. Kumar, H. Singh, A Survey on Applications of Adaptive Neuro Fuzzy Inference System, International Journal of Hybrid Information Technology, Vol.8. No.11: 343-350, (2015)

12. I. Albidewi, R. Alouhali, An Intelligent Decision Support System Using Adaptive Network-Based Fuzzy Inference System (ANFIS) For Choosing Suitable Bank Loan Installments, IOSR Journal of Computer Engineering (IOSR-JCE), Volume 16, Issue 3: 130-137.

13. A. Pranolo, F. In'ammurrohman, Y. Hendriana, D. Octaviani, A Decision Support System using ANFIS to Determine the Major of Prospective Students in A Vocational School of Indonesia, International Journal of Computer Trends and Technology (IJCTT). Volume 27. Number 2: 100-105, (2015)

14. JSR. Jang, ANFIS: Adaptive-Network-Based Fuzzy Inference System, IEEE Transactions on System, Man, and Cybernetics, Volume 23: 665- 685, (1993)

15. N. Nedjah, L. de Macedo Mourelle, Fuzzy Systems Engineering: Theory and Practice, Studies in Fuzziness and Soft Computing, Vol. 181: 53-83.

16. P. Tahmasebi, A Hybrid Neural Networks-Fuzzy Logic-Genetic Algorithm For Grade Estimation, Computers \& Geosciences. 42: 18-27, (2012) 